\title{
Fine Needle Aspiration Cytology - Utilitarian tool for Cervical Metastatic Lymphadenopathy
}

\author{
Authors \\ Dr S.A.K. Adil, Dr Bharathi. M, Dr Apoorva. N \\ Department of Pathology, Mysore Medical College and Research Institute, Mysuru, Karnataka, India \\ Corresponding Author \\ Dr Sheelashree. A. $\mathbf{N}$ \\ Department of Pathology, Mysore Medical College and Research Institute, Mysuru, Karnataka, India \\ Phone Number: 9019691259 Email: Salla291@yahoo.com
}

\begin{abstract}
Lymphadenopathy of neck region are the most frequently encountered complaints in patients referred for fine needle aspiration cytology. Fine needle aspiration cytology is a simple and effective tool for the assessment and diagnosis of cervical metastatic lymph node enlargement. In our study, conducted over a period of 4 months, we included 30 patients with metastatic deposits from various primaries, amongst which Squamous cell carcinoma was the most frequently encountered metastasis. FNAC may be recommended as a first line investigation for the evaluation of cervical neck node enlargement.

Keywords: FNAC, Metastatic nodes.
\end{abstract}

\section{Introduction}

Lymphadenopathy of neck region is most frequently encountered in patients referred for fine needle aspiration cytology. ${ }^{7}$ Numerous causes and easy accessibility of cervical nodes make FNAC as the primary workup. FNAC combined with clinical correlation can be used as first line investigation in the workup of lymph node lesions as it is simple and cost effective procedure. ${ }^{1,9}$ It is the only tool for the diagnosis and further management of the patients in some cases of metastatic malignancies. ${ }^{2}$

\section{Aim}

To study the utility of FNAC in the detection of cervical lymph node metastasis.

\section{Materials and Methods}

The study was conducted in the cytology section of Department of Pathology MMC\&RI. FNAC was performed on patients using $23 \mathrm{G}$ needle attached to 5cc syringe. Smears were fixed and stained with Papanicolaou as well as Hematoxylin \& Eosin. Lymph node aspirates found positive for metastatic deposits were included in our study. Other lymph node aspirates with inflammatory etiologies were excluded.

\section{Results}

Out of 30 patients studied, majority of the patients were above 45 years. There were 26 males and 4 females in our study and the Male to female ratio in this study was 6.5:1. The lymph nodes 
involved by malignancy were $1.5 \mathrm{~cm}$ or more in size. Amongst the cervical lymph nodes level II were involved most frequently (40\%). Metastasis to lymph nodes was clinically unsuspected in $33 \%$ of the cases. Squamous cell carcinoma was the most common tumor to metastatize to cervical lymph node with the primary most commonly from oropharynx.

\section{Table 1}

Frequencies of metastasis of various carcinomas Squamous cell carcinoma $46.6 \%$ Adenocarcinoma $3.3 \%$ Suspicious of metastatic deposits $16.6 \%$ Others $33.3 \%$

\section{Table 2}

\begin{tabular}{|cc|}
\hline $\begin{array}{c}\text { Topographic distribution of } \\
\text { lymph nodes aspirated }\end{array}$ & Frequency \\
\hline Level 1 & \\
\hline Level 2 & $30 \%$ \\
Level 3 & $40 \%$ \\
Level 4 & $6.6 \%$ \\
Level 5a & $0 \%$ \\
Level 5b & $10 \%$ \\
\hline
\end{tabular}

Table 3

\begin{tabular}{|l|c|}
\hline Site of tumour origin & Number of cases \\
\hline Oral cavity, oropharynx and larynx & 12 \\
\hline Lungs & 2 \\
\hline GIT & 3 \\
\hline Thyroid & 1 \\
\hline Breast & 1 \\
\hline Unknown & 11 \\
\hline
\end{tabular}

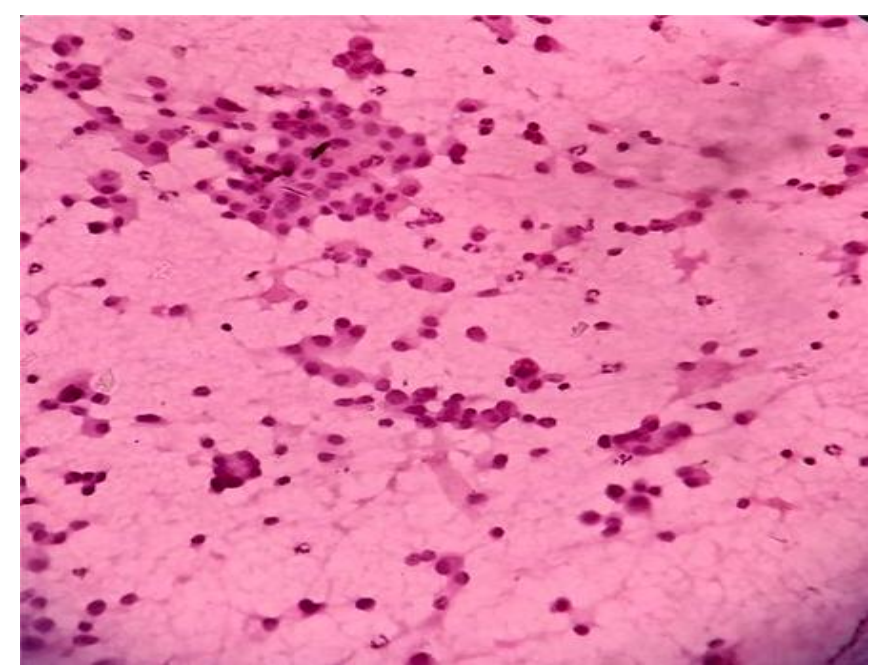

Fig 1: Photomicrograph of smear showing metastatic deposits from Medullary carcinoma of thyroid (Hematoxylin and eosin stain, 40X)

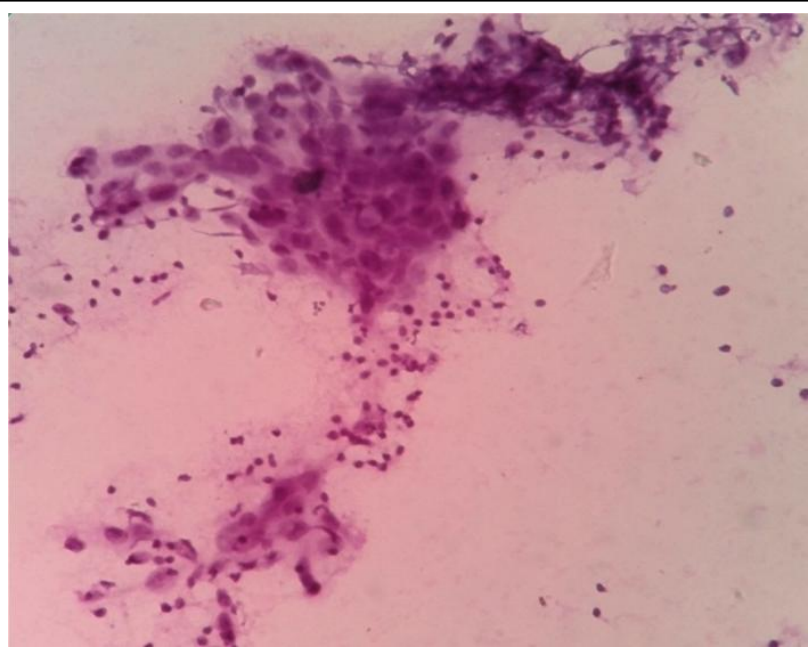

Fig.2: Photomicrograph of smear showing metastatic deposits from primary Squamous cell Carcinoma of Pyriform fossa (Hematoxylin and eosin stain, $40 \mathrm{X}$ )

\section{Discussion}

Metastastic malignancy is a more common etiology of peripheral lymphadenopathy, especially in patients over 40 years of age, the cervical group being most common to be involved. ${ }^{5,6,7}$ The diagnostic accuracy of FNAC in metastatic disease varies from $87 \%-97.9 \%{ }^{3}$

On review of literature, very few studies were done on utility of FNAC on metastatic malignant cervical lymphadenopathy.

In our study squamous cell carcinoma was the most common cytomorphological type $(46.6 \%)$ similar to other Indian studies. ${ }^{1,3,8,12}$ The primary was most often from oral cavity, pharynx and larynx $(36.6 \%)$ (Table 1 and 3). These findings were similar to the study conducted by Shamim et al $(27.7 \%){ }^{2}$ Cervical lymph nodes particularly upper cervical and posterior cervical nodes drain head and neck and may bear metastatic carcinoma originating in nasopharynx, tonsillar fossa, tongue, thyroid etc. ${ }^{1}$ In our study level II cervical nodes were most commonly involved as compared to level $\mathrm{V}$ cervical nodes involved in the study conducted by Pravin et al (Table 2). ${ }^{4}$

\section{Conclusion}

FNAC not only confirms the presence of metastatic disease but also helps in detecting origin of primary tumor, especially in cases of 
occult carcinoma. Ancillary techniques can further support the diagnosis. Fnac is useful also as a prognostic tool in metastasis to regional lymph nodes.

Sources of support in the form of grant: Nil.

\section{References}

1. Deepshikha Dave, Arpita Nishal, R. N. Hathila, Chintal Patel . Role of Fnac in the Diagnosis of Cervical Lymphadenopathy. IOSR Journal of Dental and Medical Sciences (IOSR-JDMS) . Volume 15, Issue 10 Ver. XII (Oct.. 2016), PP 48-54.

2. Shamim Sheikh, Jignesh K Parmar. Fine Needle Aspiration - A Magical Tool to Diagnose Malignant Lymphadenopathy. International Journal of Recent Trends in Science And Technology, Volume7, Issue 3, 2013 pp 138-140.

3. Dr. Poonam Woike, Dr. Ravi Bhagat, Dr. Rajesh Gaur, Dr. Dharmesh Chandra Sharma. Fine Needle Aspiration Cytology in Cervical Lymphadenopathy; A Key to Divergent Locks. IOSR Journal of Dental and Medical Sciences (IOSR-JDMS). Volume 15, Issue 8Ver. X (August. 2016), PP 118-123

4. Pravin Gojiya, Alpeshpuri Goswami, Shaila Shah. Evaluation of Fine Needle Aspiration Cytology of Cervical Lymphadenopathies at Tertiary Care Center . Annals of Pathology in laboratory medicine, Vol 5, Issue 1, January 2018,

5. Wilkinson AR, Mahore SD, Maimoon SA. FNAC in the diagnosis of lymph node malignancies: A simple and sensitive tool. Indian J Med Paediatr Oncol 2012; 33:2124.

6. Alam K, Khan A, Siddiqui F, Jain A, Haider N, Maheshwari V. Fine needle aspiration cytology (FNAC): A handy tool for metastatic lymphadenopathy. Int $\mathbf{J}$ Pathol. 2010;10:2.
7. John Miliauskas. Lymph Nodes. In: Orell, S.R., Sterrett, G.F. Textbook of Fine needle aspiration cytology, $5^{\text {th }}$ ed. India: RELX India Private limited; 2012. p. 77177.

8. Khajuria R, Goswami KC, Singh K, Dubey VK. Pattern of lymphadenopathy on fine needle aspiration cytology in Jammu. JK Sci 2006;8:157.

9. Hirachand S, Lakhey N, Akhter J, Thapa B. Evaluation of fine needle aspiration cytology of lymph nodes in Kathmandu Univ Med J. 2009;7(26):139-42

10. Shakya G, Malla S, Shakya KN, Shrestha R. Study of fine needle aspiration cytology of cervical lymph nodes. J Nepal Health Res Counc 2009; 7(14):1-5.

11. Haque MA, Talukder SI. Evaluation of fine needle aspiration cytology of lymph node in Mymensingh. Mymensingh Med J 2003;12(1): 33-5

12. Gayathri MN, Sakshi Chaurasia, Bharathi M, Shashidhar HB. Pattern of lymphadenopathy in fine needle aspiration cytology: A retrospective study. Int J Res Med Sci.2015 Jun; 3(6):1416-1419. 